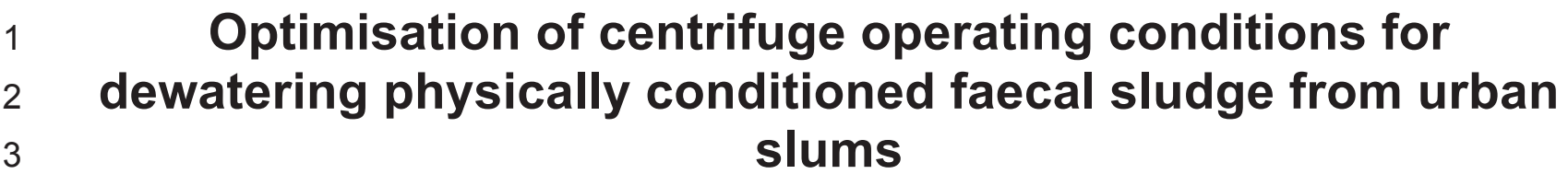

4 Swaib Semiyaga $^{a *}, M$ Mackay A. E. Okure ${ }^{b}$, Charles B. Niwagaba $^{a}$, Philip M. Nyenje $^{a}$, 5 Frank Kansiime ${ }^{c}$

aDepartment of Civil and Environmental Engineering,

$7 \quad$ College of Engineering, Design, Art and Technology; Makerere University

P.O. Box 7062, Kampala, Uganda

${ }^{\mathrm{b}}$ Department of Mechanical Engineering, College of Engineering, Design, Art and Technology; Makerere University P.O. Box 7062, Kampala, Uganda

'Department of Environmental Management, College of Agricultural and Environmental Sciences; Makerere University P.O. Box 7062, Kampala, Uganda 


\section{Optimisation of centrifuge operating conditions for dewatering physically conditioned faecal sludge from urban slums}

\section{Abstract}

Decentralised faecal sludge (FS) dewatering in urban slums using centrifugation technology has potential to reduce public health risks and environmental pollution caused by indiscriminate disposal of untreated FS. A laboratory-scale centrifuge was applied to dewater FS from lined pit latrines, conditioned with sawdust and charcoal dust. Response surface methodology and central composite design were used to construct and model relationships between independent variables (FS volume, centrifugation time and speed) and the dependent variable (per cent cake solids) for unconditioned and conditioned (sawdust and charcoal dust) FS. The results demonstrated that the centrifugation technology can yield more per cent cake solids at reduced speeds when physically conditioned. Rotational speed was a significant parameter for unconditioned (original) $(p=0.0020)$ and charcoal dust conditioned FS $(p=0.0019)$. Significant parameters for sawdust conditioned FS were speed $(p=0.0001)$ and quadratic effect of time $(p=0.0494)$. An optimal centrifugation time of 20 minutes and centrifugation container volume of $50 \mathrm{~mL}$ at $70-80 \%$ full of FS for conditioned FS were obtained. The centrifugation speeds tested in this paper provide critical information for proto-type design of a hand-powered centrifuge, the operating conditions and its subsequent set-up. This can serve as an option for dewatering FS from commonly used sanitation facilities in urban slums, thereby enabling decentralised treatment to reduce costs of FS management and support resource recovery at the source.

\section{$37 \quad$ Keywords}

Cake solids; Centrifugation speed; Centrifugation time; Faecal sludge; Response surface methodology.

\section{Introduction}

41 Over $70 \%$ of the urban population in sub-Saharan Africa (SSA) reside in slum areas (the 42 densely populated areas, lacking a road network, often located on marginal land and inhabited 43 by the poor) (UN-HABITAT, 2006). Slum dwellers rely on on-site sanitation facilities such as 44 septic tanks and pit latrines, with the later mainly in use in Kampala, Uganda, for example 45 (Nakagiri et al., 2016; Tumwebaze et al., 2013). The on-site sanitation facilities contain partially 46 digested semi-solid slurry known as faecal sludge (FS), whose management remains a 
challenge, once the facilities are full (Strande, 2014). Faecal sludge management (FSM) entails emptying/collection, transportation, treatment, end-use and/or disposal of FS. In most slum areas, infrastructure such as roads is lacking due to high density of housing units, hence making it costly and difficult for emptying trucks to access sanitation facilities. Consequently, over $50 \%$ of the generated FS remains uncollected (Blackett et al., 2014). The high FSM cost and limited access could be solved by managing FS at or near the point of generation within urban slums (decentralised level) (Semiyaga et al., 2015). However, this calls for technologies that can be used in FSM at a decentralised scale. Technologies such as gulper, vacutags, and others, have been developed to empty and collect FS from slums (Still, 2012). However, these technologies cannot solve all challenges of the FSM services chain such as the treatment and disposal or end-use of FS.

Since FS is over $90 \%$ water, dewatering presents an important first step of treating it effectively. A new pit latrine design incorporated with a removable dewatering unit (metal cage with filter bags) could be an innovative approach to reduce the cost of dewatering, emptying and subsequent transportation of FS (Hamawand and Lewis, 2016). The containers can easily be collected from places with limited access in slums. However, the high percentage of filled-up pit latrines, reported at $66 \%$ in the slums of Kampala (Nakagiri et al., 2015), and the limited space for new ones, would call for technologies of managing/dewatering FS from the already existing filled-up latrines. Technologies commonly used in dewatering sewage sludge at a centralised scale include; thickening tanks, sand beds, filter presses and centrifuges (Pan et al., 2003). The sand bed and filter press technologies have a challenge of large space requirement which may be limited in urban slum settings. Centrifugation technology has a small foot print in terms of area requirement, low operation costs and normally has a casing to enclose odour in densely populated areas (Broadbent, 2001; Drury et al., 2002). In addition, dewatering or sedimentation can be achieved faster due to enhancement of gravitational acceleration by centrifugal acceleration resulting from circular rotational motion of the centrifuge (Garrido et al., 2003). Such characteristics make centrifugation an appropriate dewatering technology for urban slums.

74 Centrifugation is based on the principle that when a suspension such as FS is swirled at a particular rotational speed, the denser solids move through a fluid in the direction tangential to the direction of rotation, under centrifugal acceleration (Vesilind and Zhang, 1984). A driving force for water removal from settled FS sets up, which reduces the cake moisture content (or increasing per cent dry cake solids) in the settled solid fraction of FS. However, the use of 
rotational speed to hasten dewatering during centrifugation requires mechanical energy say from electric motors, hence, high operational and maintenance costs. This further limits their widespread application in some slum areas with no connection to the electricity grid.

Industrial /commercial centrifuges have been classified into sedimenting or filtering centrifuges, with underlying principles of gravity sedimentation and pressure filtration, respectively (Buerger and Concha, 2001). Extensive usage of sedimenting centrifuges has been reported, and it has been found that suspensions containing considerable amount of fine solids of less than $45 \mu \mathrm{m}$ easily clog filtering centrifuges (Buerger and Concha, 2001). Semiyaga et al. (2017a) reported that FS from pit latrines in Kampala slums contain over $70 \%$ fine particles of less than $45 \mu \mathrm{m}$, justifying the need for sedimentation centrifuge type.

Data from batch laboratory-scale centrifugation studies have been used as a basis for design equations of large-scale continuous centrifuges or to know the performance of existing centrifuges, given the type of feedstock to be centrifuged (Brar et al., 2006). Continuous commercial centrifuges are designed on mechanical basis and cannot be easily modified. Indeed, centrifuge design is impossible in the absence of laboratory centrifugation studies. The performance of a commercial continuous centrifuge is governed by equation (1) (Brar et al., 95 2006).

$$
\Sigma=\frac{Q t \omega^{2}}{g \ln \left(R_{0} / R_{1}\right)}
$$

97 Where $\Sigma$ is the centrifuge parameter, dimension $L^{2}\left(m^{2}\right) ; Q$ is the feedstock flow rate $(1 / d)$, which 98 is proportional to volume; $t$ is the centrifugation time $(\mathrm{s}) ; g$ is the acceleration due to gravity $99\left(9.81 \mathrm{~ms}^{-2}\right) ; \omega$ is the rotational speed $\left(\operatorname{rads}^{-1}\right) ; R_{0}$ is the maximum rotor radius $(\mathrm{cm}) ; R_{1}$ is the 100 minimum radius of liquid interface $(\mathrm{cm})$. However, since some parameters are constant, volume 101 of FS, rotational speed and time are the major operational parameters pertinent for the batch 102 centrifugation process (Buerger and Concha, 2001).

103 Cake solids formation depends on both centrifugation operating conditions such as rotational 104 speed, time, nature of FS material centrifuged, as well as the form of material pre-treatment 105 such as using conditioners. Centrifugation has a drawback of achieving dewatering at very high 106 rotational speeds. Pre-treatment of FS with chemical conditioners improves the dewatering rate 107 or rate of cake formation (Gold et al., 2016). However, physical conditioners such as char, 
sawdust, bagasse, wheat dregs, coal fines and rice husks are reported to improve the extent of dewatering (cake dryness or per cent dry solids in FS cake) and partly the dewatering rate (rate at which water filters out of FS) (Qi et al., 2011). The physical conditioners, being at lower moisture content absorb moisture from FS and also enhance the mechanical strength of the resulting cake by formation of rigid lattice structures which improve porosity of sludge cake; hence easing flow of water out of the cake (Qi et al., 2011; Semiyaga et al., 2017b).

Sawdust and charcoal dust conditioners are wastes from timber saw mills and wood charcoal, respectively. They have advantages of being biodegradable, readily available in urban slums at low or no cost, and the dewatered cake has improved utilisation potential especially during energy recovery (Diener et al., 2014). Sawdust and charcoal dust can improve dewatering extent and, hence a probable reduction in rotational speed required for centrifugation. However, when FS is conditioned and centrifuged, the centrifugation operation conditions of FS volume, rotational speed and time act differently and can affect one another. Consequently, optimization of these factors is necessary in order to determine the best response in terms of per cent cake solids achieved. In addition, centrifuges have been used in centralised wastewater treatment plants, but no studies exist on decentralised centrifugation of FS from pit latrines in slums areas.

This study was therefore carried out to determine the effect of sawdust and charcoal dust conditioning on optimum centrifugation operation parameters of FS. This study is considered of benefit to the process design and sizing efficient equipment pertinent in dewatering of FS from the sanitation facilities commonly used in urban slums, such as pit latrines. FS from lined pit latrines was considered in this study. This is because a study by Semiyaga et al. (2017a) revealed that FS from lined pits had a lower dewatering extent compared to FS from unlined pit latrines.

\section{Materials and methods}

\subsection{Collection of FS samples}

FS samples for the study were collected from Bwaise, a typical urban slum in Kampala (Uganda) with limited access to mechanised pit emptying. A fabricated multi-stage sampler reported by Semiyaga et al. (2017a) was used in obtaining FS samples from five purposively selected pit latrines. Grab samples of one litre were obtained from each of the three layers (top, middle and bottom) of each pit latrine through a squat hole and were mixed into a composite sample. Composite samples were obtained from five pit latrines and put in a 30 litre HDPE 
plastic container. The container was immediately transported to the Public Health and Environmental Engineering Laboratory at Makerere University. While in the laboratory, the samples were stored at $4^{\circ} \mathrm{C}$ until they were analysed. Prior to preparation and subsequent experiments, FS samples were removed from the refrigerator and left to attain room

143 temperature.

\section{$144 \quad 2.2$ Preparation of FS samples}

145 Preparation of FS samples before analysis involved passing them through a $5 \mathrm{~mm}$ sieve to 146 remove the extraneous materials (Burton, 2007; Semiyaga et al., 2017a). The raw FS samples 147 from lined pit latrines were characterised for total solids (TS), total volatile solids (TVS), ash 148 content, $\mathrm{pH}$, electrical conductivity (EC), sand content and bulk density (Table 1). TS, TVS and 149 ash content of FS were determined according to standard methods (APHA/AWWA/WEF, 2012). 150 EC and $\mathrm{pH}$ were measured using a calibrated portable meter (Hach HQ30d Flexi model). The 151 TS concentration was determined gravimetrically by taking the weight of an oven dried sample 152 at $105^{\circ} \mathrm{C}$ for 24 hours and expressed as a fraction of raw sample volume. TVS was determined 153 by taking the weight difference between oven dried solids and the 2-hour muffle furnace ignited 154 sample at $550^{\circ} \mathrm{C}$ and expressed as a percentage of TS. Ash content was the residue weight 155 after ignition in the furnace at $550^{\circ} \mathrm{C}$ for 2 hours, also expressed as a percentage of TS. Sand content was determined using the acid method; where ash was washed with $0.1 \mathrm{M} \mathrm{HCl}$ solution into ash-less filter papers. The paper and content were ignited in a furnace at $550^{\circ} \mathrm{C}$ for 2 hours and the residue was taken as sand content, expressed as a percentage of TS. Three replicates were analysed for each sample to attest the reproducibility of the experimental results.

Table 1 Characteristics of original faecal sludge samples from pit latrines

\begin{tabular}{lll}
\hline Parameter & Unit & Mean values $\pm S D$ \\
\hline $\mathrm{pH}$ & & \\
Electrical conductivity & $\mathrm{mS} \mathrm{cm}^{-1}$ & $7.77 \pm 0.03$ \\
Temperature & ${ }^{\circ} \mathrm{C}$ & $24.4 \pm 0.6$ \\
Total solids (TS) & $\mathrm{gL}^{-1}$ & $31.0 \pm 0.8$ \\
Moisture content & $\%$ & $97.0 \pm 0.1$ \\
Total volatile solids (TVS) & $\% \mathrm{TS}$ & $58.6 \pm 0.5$ \\
Ash content & $\% \mathrm{TS}$ & $41.4 \pm 0.5$ \\
Sand content & $\% \mathrm{TS}$ & $31.2 \pm 5.6$ \\
Bulk density & $\mathrm{kgm}^{-3}$ & $1240 \pm 0.3$ \\
\hline
\end{tabular}

Notes: $S D$ standard deviation. 


\subsection{Faecal sludge conditioning}

163 Preliminary conditioning experiments were performed on FS by varying sawdust and charcoal 164 dust conditioner dosages from $0,25,50,75$ and $125 \%$ (weight of dry conditioner as a ratio of 165 FS dry solids). Sawdust and charcoal dust dosage of $75 \%$ FS total solids had the optimal 166 dewaterability efficiency (for both indicators of dewatering rate and dewatering extent) 167 (Semiyaga et al. unpublished results). Therefore, in this study, FS was conditioned with sawdust 168 and charcoal dust dosages of 75 \% TS. Charcoal dust was obtained from charcoal outlets within 169 Bwaise slum, while sawdust was obtained from a timber sawing mill in the same slum area. 170 Charcoal dust and sawdust particles were sieved to a size less than $2.36 \mathrm{~mm}$ to limit variability, 171 oven dried for 24 hours and stored in a vacuum desiccator, for consistency in dry weight during 172 analysis (Luo et al., 2013). The characteristics and particle size distribution of sawdust and 173 charcoal dust are presented in Table 2 and Table 3, respectively.

Table 2 Characteristics of physical conditioners (sawdust and charcoal dust)

\begin{tabular}{llll}
\hline & Unit & Sawdust & Charcoal dust \\
\hline Specific gravity & & 0.065 & 0.053 \\
Bulk density (loose) & $\mathrm{kgm}^{-3}$ & $173.9 \pm 10.8$ & $868.5 \pm 7.8$ \\
Water content (wet basis) & $\mathrm{wt} \%$ & $18.4 \pm 1.3$ & $11.6 \pm 0.4$ \\
TVS & $\mathrm{wt} \%$ & $79.0 \pm 1.0$ & $61.3 \pm 2.2$ \\
Ash content & $\mathrm{wt} \%$ & $2.5 \pm 0.6$ & $24.7 \pm 3.1$ \\
Gross heating value (dry basis) & $\mathrm{MJkg}^{-1}$ & $19.7 \pm 0.1$ & $23.7 \pm 0.7$ \\
Crude protein & $\mathrm{mg} \mathrm{g}^{-1}$ solids & 2.6 & 10.3 \\
\hline
\end{tabular}

Table 3 Particle size distribution of sawdust and charcoal dust conditioners (Semiyaga et al., 2017b)

\begin{tabular}{lcccc}
\hline \multirow{2}{*}{$\begin{array}{l}\text { Particle size } \\
(\mathrm{mm})\end{array}$} & \multicolumn{2}{c}{ Sawdust } & \multicolumn{2}{c}{ Charcoal dust } \\
\cline { 2 - 5 } & $\begin{array}{c}\text { Mass retained } \\
(\%)\end{array}$ & $\begin{array}{c}\text { Cumulative mass } \\
\text { passing }(\%)\end{array}$ & $\begin{array}{c}\text { Mass retained } \\
(\%)\end{array}$ & $\begin{array}{c}\text { Cumulative mass } \\
\text { passing }(\%)\end{array}$ \\
\hline 2.360 & 0.0 & 100.0 & 0.0 & 100.0 \\
1.180 & 36.6 & 63.4 & 31.4 & 68.6 \\
0.600 & 37.4 & 26.0 & 22.6 & 46.0 \\
0.425 & 11.6 & 14.4 & 9.4 & 36.6 \\
0.300 & 7.2 & 7.2 & 8.9 & 27.7 \\
0.212 & 3.6 & 3.6 & 6.4 & 21.3 \\
0.150 & 1.6 & 2.0 & 5.2 & 16.1 \\
0.750 & 0.8 & 1.2 & 7.2 & 8.9 \\
Pan & 1.2 & N/A & 8.9 & N/A \\
\hline
\end{tabular}

\subsection{Centrifugation experimental design}

179 A laboratory based electrical centrifuge (MISTRAL1000 type, UK) equipped with four centrifuge 180 cells of $50 \mathrm{~mL}$ capacity each, with a respective rotational speed and time limit of $6000 \mathrm{rpm}$ 181 (centrifugal acceleration of $6040 \mathrm{~g}$ ) and 99 seconds was used in the study. Centrifugation 
experiments were carried out by varying independent variables (factors) of FS volume,

183 rotational speed and time to obtain the dependent variable of percent cake solids (dewatering

184 extent) for different factors. A predetermined FS volume was centrifuged at a particular speed

185 for a known time. The dry solids of the settled dewatered cake obtained at oven temperature of

$186105^{\circ} \mathrm{C}$ and expressed as a percentage of wet dewatered cake was taken as per cent cake 187 solids. The following minimum and maximum values of factors were used; volume $(30-50 \mathrm{~mL})$, 188 speed (600-1800 rpm, with respective centrifugal accelerations of 60-540 g) and time (10-30 189 minutes).

190 Combinations of different factors were determined using the central composite design (CCD) 191 and response surface methodology (RSM) in JMP software package, version 10 (SAS Institute).

192 CCD and RSM were used for constructing and exploring approximate relationships between the 193 independent variables of the centrifugation process (i.e. FS volume, speed and time) and the 194 response variable (per cent cake solids). The mentioned range values for the factors were 195 entered in JMP software and 16 runs were automatically generated (Table 4) with different 196 combinations of volume, speed and time.

197 Table 4: Central composite design for experimental variables (volume, rotational speed and time) and response (\% 198 cake solids).

\begin{tabular}{ccccccc}
\hline Run No. & Volume $(\mathrm{mL})$ & $\begin{array}{c}\text { Speed } \\
\text { (RPM) }\end{array}$ & Time $(\mathrm{min})$ & \multicolumn{3}{c}{ Cake solids (\%) } \\
\cline { 5 - 6 } & & & Original FS & $\begin{array}{c}\text { Sawdust } \\
\text { conditioner }\end{array}$ & $\begin{array}{c}\text { Charcoal dust } \\
\text { conditioner }\end{array}$ \\
\hline 1 & 30 & 600 & 10 & 8.7 & 11.2 & 12.1 \\
2 & 30 & 600 & 30 & 9.1 & 11.9 & 14.8 \\
3 & 30 & 1200 & 20 & 10.9 & 14.1 & 18.9 \\
4 & 30 & 1800 & 10 & 12.3 & 14.9 & 17.6 \\
5 & 30 & 1800 & 30 & 12.0 & 15.6 & 16.8 \\
6 & 40 & 600 & 20 & 9.5 & 14.0 & 14.5 \\
7 & 40 & 1200 & 10 & 10.8 & 13.4 & 15.3 \\
8 & 40 & 1200 & 20 & 11.0 & 14.1 & 16.7 \\
9 & 40 & 1200 & 20 & 14.1 & 15.3 & 18.2 \\
10 & 40 & 1200 & 30 & 12.2 & 14.9 & 17.4 \\
11 & 40 & 1800 & 20 & 13.8 & 16.7 & 19.2 \\
12 & 50 & 600 & 10 & 10.1 & 12.6 & 13.6 \\
13 & 50 & 600 & 30 & 9.5 & 11.7 & 14.1 \\
14 & 50 & 1200 & 20 & 12.2 & 15.3 & 17.8 \\
15 & 50 & 1800 & 10 & 13.2 & 15.6 & 15.8 \\
16 & 50 & 1800 & 30 & 13.2 & 16.5 & 19.6 \\
\hline
\end{tabular}

199 The objective was to maximise the per cent cake solids for the various combinations of 200 independent variables. The values of per cent cake solids shown in Table 4 were obtained 201 experimentally for 16 runs of original FS (FS without conditioners), 16 runs (each) of sawdust 202 and charcoal dust conditioned FS. Experiments were carried out using two replicates, hence, 203 each per cent cake solid value reflecting average of the replicates. 


\subsection{Data analysis}

Statistical design of experiments and data analysis was performed using the statistical software package JMP, version 10 (SAS Institute) for the regression analysis of the data and to estimate the coefficient of regression equations. The experimental data obtained (Table 4) was modelled by the system described through an empirical second-order equation (Eq. 2). Second order model gives a good estimate of the response surface and can be used to locate optimum response (\% cake solids) and at the same time explain the centrifugation process.

$$
Y=\beta_{0}+\sum_{i=1}^{k} \beta_{i} x_{i}+\sum_{i=1}^{k} \beta_{i i} x_{i}^{2}+\sum_{i=1}^{k} \sum_{i \neq j=1}^{k} \beta_{i j} x_{i} x_{j}+\varepsilon
$$

212 Here, $\mathrm{Y}$ is the predicted response or dependent variable ( $\%$ cake solids); $\beta_{0}$ is a constant 213 coefficient (intercept); $\beta_{i}, \beta_{i i}$ and $\beta_{i j}$ refer to the regression coefficient for linear, quadratic, and 214 interaction effects (between factors $i$ and $j$ ), respectively; $x_{i}$ and $x_{j}$ are the independent 215 variables (i.e. FS volume, centrifugation speed and time); $k$ is the number of factors 216 (independent variables) and $\varepsilon$ denotes the random error of prediction (residuals).

217 The estimates of the model coefficients were calculated by least squares multiple regression. 218 Analysis of variance (ANOVA) was used for model adequacy and analysis of experimental data 219 to obtain the interaction between the independent variables and the response. The statistical 220 significance of the model was checked by Fisher's F-test and the quality of model fit was 221 expressed by the regression coefficient $R^{2}$. The significance of the model terms in Eq. 2 were 222 evaluated at $p$-values $\leq 0.05$ (95\% confidence interval). The mathematical equations for original 223 and conditioned FS which relate factors and the response were developed. Thereafter, the non224 significant model terms $(p>0.05)$ were eliminated to obtain reduced model equations. The 225 validity of the reduced model equations (after dropping the non-significant terms) were checked 226 by computing the model residuals and examining the normal probability plots. A reduced model 227 was considered valid when the residual plots were very close to a straight line (normally 228 distributed). Lastly, canonical curvature analysis was performed to predict the shape of the 229 curve generated by the multiple regression models. Three-dimensional (3D) surface plots and 230 their respective two-dimensional (2D) contour plots were obtained for the original and physical 231 conditioned (sawdust and charcoal dust) FS, based on response (\% cake solids) and the 232 independent variables (FS volume, centrifugation speed and time). 


\section{Results}

\subsection{Statistical analysis of models for original and conditioned FS}

The regression coefficient $\left(R^{2}\right)$ values for models of original, sawdust and charcoal dust conditioned FS of $0.84,0.94$ and 0.88 , respectively, indicate that respective 84,94 and $88 \%$ of the variations in per cent cake solids (response) can be explained by the factors of FS volume, speed and time. Models for conditioned and original FS used were significant $(p=0.005$ and 0.034 for sawdust and charcoal dust conditioned FS, respectively) (Table 5). The probability of lack of fit (PLOF) for original and conditioned FS were more than 0.05 , implying that the secondorder model fits the experimental data well and thus its application is eligible to interpret the response values of per cent cake solids. Additionally, the sawdust conditioned FS model was better explainable by variables because of the higher $R^{2}$ and $\operatorname{Adj} R^{2}$. Concurrently, a relatively lower coefficient of variation (CV) for the same model of $11.8 \%$ indicated a more precise and reliable model.

Table 5: ANOVA and model fitting results for the response (\% cake solids) for original and conditioned FS

\begin{tabular}{lllllllll}
\hline & $\mathrm{P}$ & $R^{2}$ & Adj. $R^{2}$ & CV $(\%)$ & RMSE & MOR & PLOF & F-value \\
\hline Original (FS only) & 0.067 & 0.84 & 0.61 & 15.0 & 1.07 & 11.4 & 0.98 & 0.08 \\
FS + Sawdust & $0.005^{*}$ & 0.94 & 0.85 & 11.8 & 0.65 & 14.2 & 0.78 & 0.51 \\
FS + Charcoal dust & $0.034^{*}$ & 0.88 & 0.70 & 13.3 & 1.20 & 16.4 & 0.57 & 1.34 \\
\hline
\end{tabular}

Notes: P - probability; PLOF - probability of lack of fit; CV - coefficient of variation; RMSE - root mean square error; MOR - mean of response; *Statistically significant at $p<0.05 . \mathrm{F}=$

The coefficient estimates of the regression terms for original and conditioned FS were obtained from JMP software output (Table 6); resulting in the equations $(3,4$, and 5$)$ for original, sawdust and charcoal dust conditioned FS, respectively. The response (\% cake solids), denoted as $\mathrm{Y}$, while the factors of FS volume, speed and time were coded as $x_{1}, x_{2}$ and $x_{3}$, respectively.

$$
Y=12.16+0.52 x_{1}+1.76 x_{2}+0.09 x_{3}+0.04 x_{1} x_{2}-0.09 x_{1} x_{3}-0.01 x_{2} x_{3}-0.42 x_{1}{ }^{2}-0.32 x_{2}{ }^{2}-0.47 x_{3}{ }^{2}
$$

$$
Y=14.99+0.40 x_{1}+1.79 x_{2}+0.29 x_{3}+0.05 x_{1} x_{2}-0.18 x_{1} x_{3}+0.23 x_{2} x_{3}-0.43 x_{1}^{2}+0.22 x_{2}^{2}-0.98 x_{3}^{2}
$$

$$
Y=17.75+0.07 x_{1}+1.99 x_{2}+0.83 x_{3}+0.03 x_{1} x_{2}+0.30 x_{1} x_{3}-0.03 x_{2} x_{3}+0.44 x_{1}^{2}-1.06 x_{2}^{2}-1.56 x_{3}^{2}
$$


257 Table 6: Model parameter estimates and ANOVA results for response surface second-order model terms 258 for per cent cake solids

\begin{tabular}{|c|c|c|c|c|c|c|}
\hline & Model term & $\begin{array}{l}\text { Coefficient } \\
\text { estimate }\end{array}$ & $\begin{array}{l}\text { Degrees of } \\
\text { freedom }\end{array}$ & $\begin{array}{l}\text { Sum of } \\
\text { squares }\end{array}$ & F-value & $\begin{array}{l}P \text {-value } \\
(P>F)\end{array}$ \\
\hline \multirow[t]{10}{*}{ Original } & Intercept & 12.16 & & & & $<0.0001^{*}$ \\
\hline & $\mathrm{X}_{1}$ & 0.52 & 1 & 2.70 & 2.34 & 0.1766 \\
\hline & $\mathrm{X}_{2}$ & 1.76 & 1 & 30.98 & 26.86 & $0.0020^{*}$ \\
\hline & $x_{3}$ & 0.09 & 1 & 0.08 & 0.07 & 0.7999 \\
\hline & $\mathrm{X}_{1} \mathrm{X}_{2}$ & 0.04 & 1 & 0.01 & 0.01 & 0.9245 \\
\hline & $X_{1} X_{3}$ & -0.09 & 1 & 0.06 & 0.05 & 0.8254 \\
\hline & $x_{2} X_{3}$ & -0.01 & 1 & 0.00 & 0.00 & 0.9748 \\
\hline & $X_{1} X_{1}$ & -0.42 & 1 & 0.46 & 0.39 & 0.5530 \\
\hline & $x_{2} X_{2}$ & -0.32 & 1 & 0.26 & 0.23 & 0.6502 \\
\hline & $X_{3} X_{3}$ & -0.47 & 1 & 0.57 & 0.50 & 0.5079 \\
\hline \multirow[t]{10}{*}{ FS + Sawdust } & Intercept & 14.99 & & & & $<0.0001^{*}$ \\
\hline & $\mathrm{X}_{1}$ & 0.40 & 1 & 1.60 & 3.78 & 0.1000 \\
\hline & $\mathrm{X}_{2}$ & 1.79 & 1 & 32.04 & 75.62 & $0.0001^{*}$ \\
\hline & $\mathrm{X}_{3}$ & 0.29 & 1 & 0.84 & 1.98 & 0.2085 \\
\hline & $\mathrm{X}_{1} \mathrm{X}_{2}$ & 0.05 & 1 & 0.02 & 0.05 & 0.8352 \\
\hline & $X_{1} X_{3}$ & -0.18 & 1 & 0.25 & 0.58 & 0.4758 \\
\hline & $x_{2} x_{3}$ & 0.23 & 1 & 0.41 & 0.96 & 0.3660 \\
\hline & $X_{1} X_{1}$ & -0.43 & 1 & 0.50 & 1.17 & 0.3201 \\
\hline & $X_{2} X_{2}$ & 0.22 & 1 & 0.12 & 0.29 & 0.6102 \\
\hline & $X_{3} X_{3}$ & -0.98 & 1 & 2.56 & 6.03 & $0.0494^{*}$ \\
\hline \multirow[t]{10}{*}{$\mathrm{FS}+$ Charcoal dust } & Intercept & 17.75 & & & & $<0.0001^{*}$ \\
\hline & $\mathrm{X}_{1}$ & 0.07 & 1 & 0.05 & 0.03 & 0.8598 \\
\hline & $\mathrm{X}_{2}$ & 1.99 & 1 & 39.60 & 27.49 & $0.0019^{*}$ \\
\hline & $\mathrm{X}_{3}$ & 0.83 & 1 & 6.89 & 4.78 & 0.0714 \\
\hline & $X_{1} X_{2}$ & 0.03 & 1 & 0.01 & 0.00 & 0.9549 \\
\hline & $x_{1} x_{3}$ & 0.30 & 1 & 0.72 & 0.50 & 0.5061 \\
\hline & $X_{2} X_{3}$ & -0.03 & 1 & 0.01 & 0.00 & 0.9549 \\
\hline & $X_{1} X_{1}$ & 0.44 & 1 & 0.52 & 0.36 & 0.5694 \\
\hline & $X_{2} X_{2}$ & -1.06 & 1 & 2.94 & 2.04 & 0.2034 \\
\hline & $X_{3} X_{3}$ & -1.56 & 1 & 6.38 & 4.43 & 0.0801 \\
\hline
\end{tabular}

259 Notes: * statistically significant at $p<0.05$

260 When the significance of each term's contribution to the three model equations $(3,4$ and 5$)$ was 261 determined, it suffices to note that the intercept coefficient terms for all the three models were 262 highly significant ( $p<0.0001$ for equations 3,4 and 5 , each). The linear coefficients of speed 
significantly contributed to $\%$ cake solids for all the three models $(p=0.0020,0.0001$ and 0.0019 for original, sawdust and charcoal dust conditioned FS, respectively). However, the quadratic effect of time had significant contribution $(p=0.0494)$ to $\%$ cake solids for only sawdust conditioned FS.

After elimination of non-significant terms, reduced model equations for original and charcoal dust conditioned FS were still valid, since residual plots were close to a straight line (Supplementary S1). Unlike for sawdust conditioned FS, the significant terms of speed and time $^{2}$ had plots quite away from the straight line. An adjustment was therefore made to avoid eliminating the terms for speed ${ }^{2}$ and the interaction of speed and time. This produced a plot, where the residual plots were very close to the straight line (Supplementary S1). After eliminating model terms and checking for validity, the following reduced equations 6,7 and 8 for original, sawdust and charcoal dust conditioned FS respectively were generated. These can be reliably used to produce \% cake solids for different factor consideration.

$276 \quad Y=12.16+1.76 x_{2}$

$277 Y=14.99+1.79 x_{2}+0.23 x_{2} x_{3}+0.22 x_{2}^{2}-0.98 x_{3}^{2}$

$278 \quad Y=17.75+1.99 x_{2}$

\subsection{Effects of parameters on process optimisation}

280 The regression model equations were graphically represented on three-dimensional (3D) 281 surface and two-dimensional (2D) contour plots for the original, sawdust and charcoal dust 282 conditioned FS from pit latrines. This was to visualise the relationship between interaction of 283 independent variables and the corresponding per cent cake solids yield under these conditions.

When the original FS was centrifuged under varying conditions of volume, speed and time, the mean of \% cake solids for all runs was $11.4 \%$ (Table 5). Increase in time from 5 to 20 minutes at volumes of $20 \mathrm{~mL}$ or speed of $400 \mathrm{rpm}$ only improved cake solids from 8 to $9 \%$. Increase in volume (40-50 mL) by about twice at the same time of 20 minutes increased cake solids from 8 to $12.3 \%$ (Figure 1). Time increase beyond 20 minutes generally reduced the per cent cake solids. The converging of contours reflected interactions between; volume and time (elliptical contours reflect a perfect interaction between volume and time), volume and speed; and time 291 and speed, although the interactions were not significantly changing the per cent cake solids ( $p$ 292 > 0.05). However, visualising the way the various factors influence the dewatering process helps to improve the centrifuge design. 
294 Furthermore, at optimal rotational time of 20 minutes and volume of $\sim 45 \mathrm{~mL}$, the average \% cake solids of 11.4 (Table 5) could be achieved at a speed of $920 \mathrm{rpm}$. Increase in speed from 400 to $2000 \mathrm{rpm}$ linearly improved \% cake solids at slight quadratic effects of volume and time (Figure $1 \mathrm{~b}$ and c). Similarly, increasing speed from 920 to $2000 \mathrm{rpm}$ at constant time of 20 minutes improved \% cake solids from average of 11.4 to $14.1 \%$ (Figure 1c).

(a)

303

305

312

314

316

318

320

322

324

326

328

330

332

334

336

338

340

342

344

345

346

347

348
300

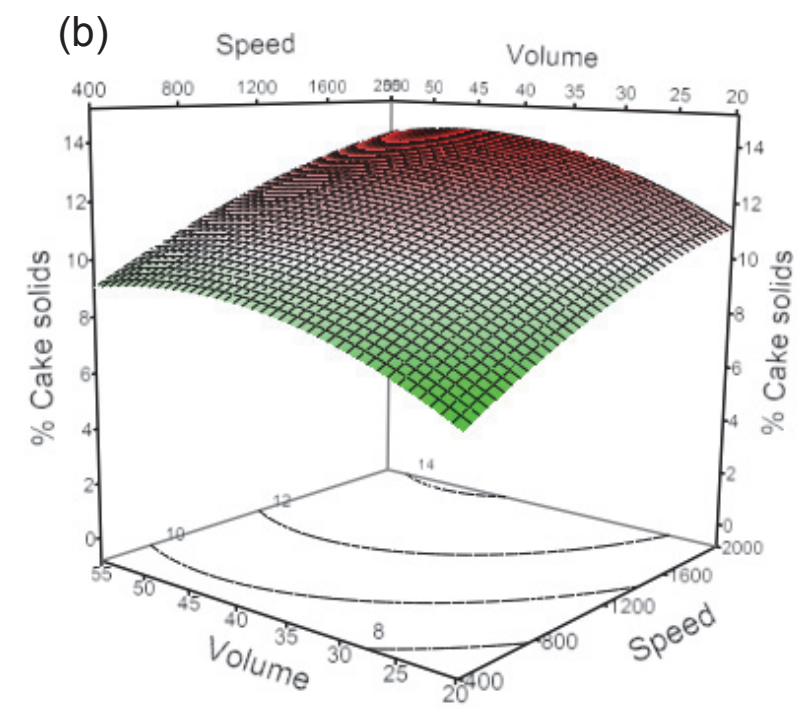

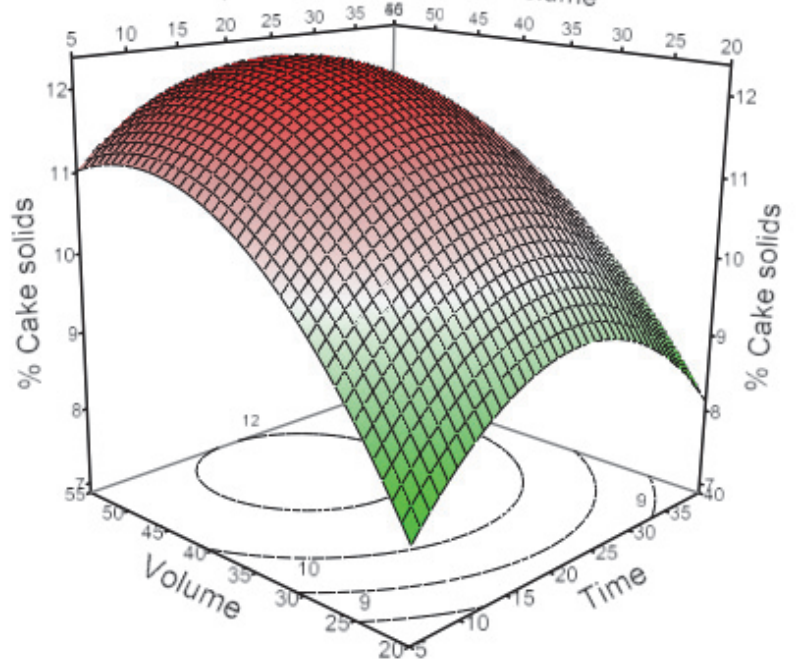

Volume

(c)

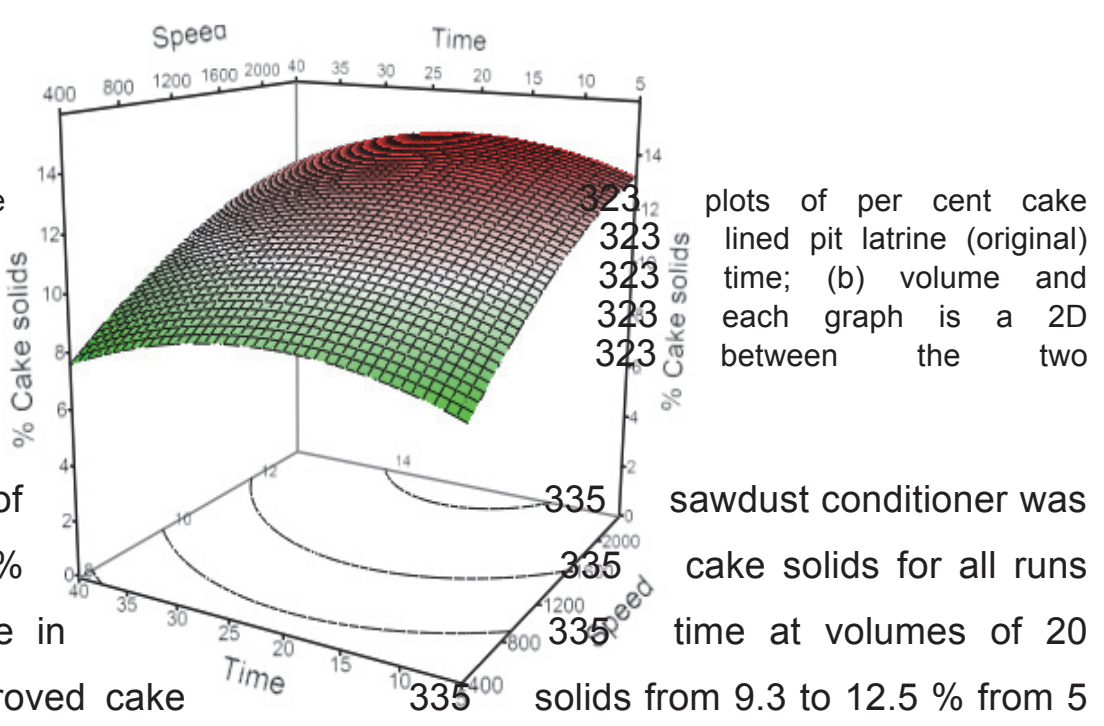

Figure 1 Three-dimensional surface solids for unconditioned FS from as a function of: (a) volume and speed; (d) time and speed. Below contour plot showing interaction variables.

When 75 \% TS dosage of mixed with FS, the mean of \% increased to $14.2 \%$. Increase in $\mathrm{mL}$ or speed of $400 \mathrm{rpm}$ improved cake ${ }_{\text {Time }}{ }^{15}{ }^{10} 335^{400}$ solids from 9.3 to $12.5 \%$ from 5 to 20 minutes, respectively. Increase in volume $(40-50 \mathrm{~mL})$ by about twice, at the same time of 20 minutes, increased cake solids from 9.3 to $15 \%$ (Figure 2a). Time increase beyond 20 minutes generally reduced the per cent cake solids. The 2D contours reflect some interactions between; volume and time (also, the elliptical contours reflect a perfect interaction between volume and time), volume and speed; time and speed. The speed and quadratic effect of time 
349 were significantly contributing to the per cent cake solids for sawdust conditioned FS ( $p=$ 3500.0001 and $p=0.0494$, respectively). At optimal time of 20 minutes and volume of $\sim 45 \mathrm{~mL}$, the 351 average per cent cake solids of 14.2 (Table 5) could be achieved at speed of 890 rpm. Similarly, 352 the $11.2 \%$ cake solids at a rotational speed of $920 \mathrm{rpm}$ in the original FS can be achieved at 353 virtually no rotation, but only through sedimentation or absorption effect. Increase in speed from 354400 to $2000 \mathrm{rpm}$ linearly improved per cent cake solids at slight quadratic effects of volume and 355 time (Figure $2 \mathrm{~b}$ and c). Similarly, increasing speed from 890 to $1800 \mathrm{rpm}$, at a constant time of 35620 minutes, improved per cent cake solids from average of 14.2 to $17.0 \%$ (Figure 2c). 
(a)

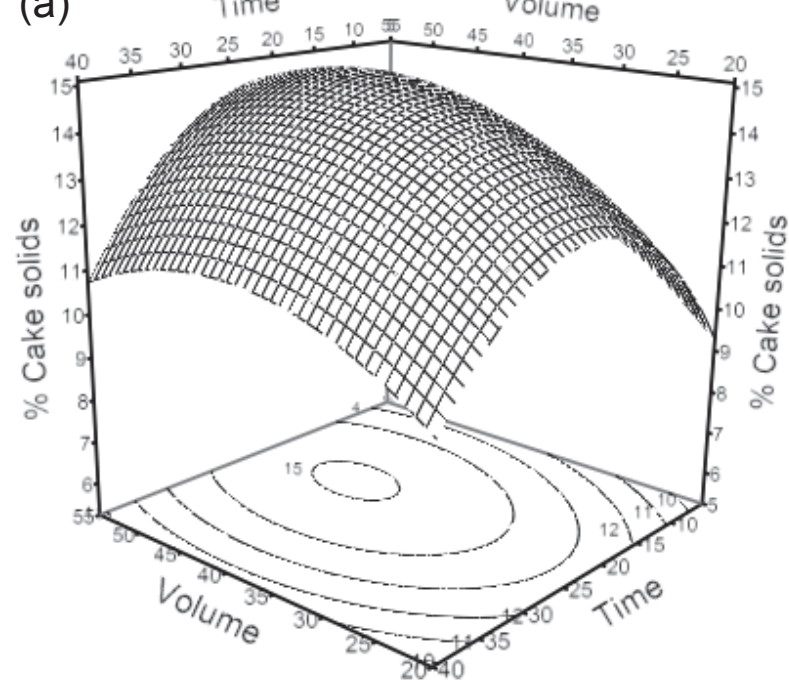

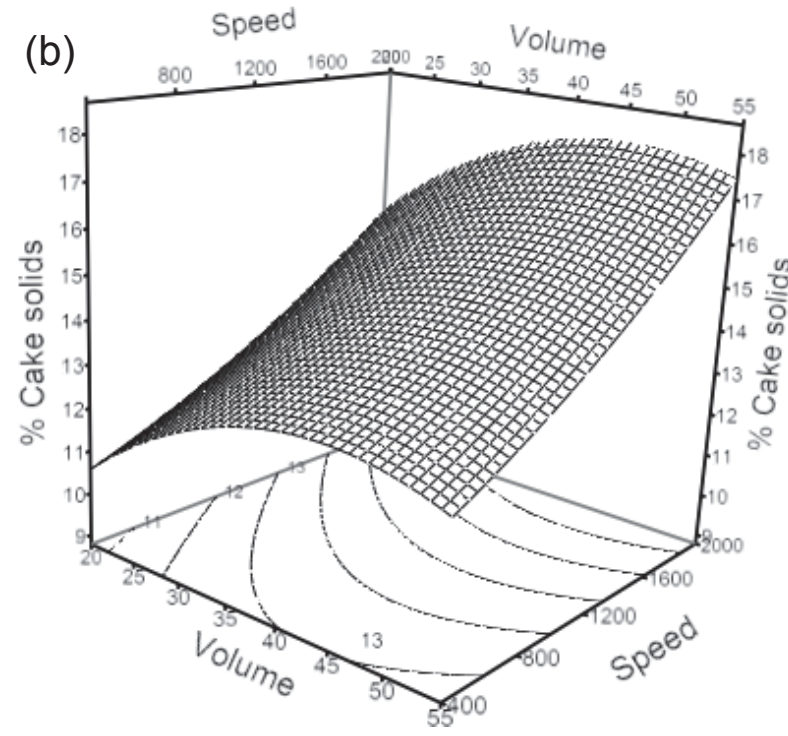

Figure 2 Three-dimensional surface plots of per cent cake solids for sawdust-conditioned pit latrine FS as a function of: (a) volume and time; (b) volume and speed; (d) time and speed. Below each graph is a 2D contour plot showing interaction between the two variables.

A $75 \%$ TS dosage of charcoal dust conditioner mixed with FS increased the mean of per cent cake solids for all runs to $16.4 \%$ (Table 5). Per cent cake solids increased at lower and higher volumes, with the least observed values at intermediate volumes at all times. However, the maximums at lower $(<30 \mathrm{~mL})$ and higher volumes $(>42 \mathrm{~mL})$ and minimum at intermediate volume $(35 \mathrm{~mL})$, all occurred at time of 20 minutes (Figure 3a). Thus, some interactions of volume and time were realised at lower and higher volumes, although not significant $(p=$ 0.506). A similar effect on volume interaction with speed was observed at lower and higher 
387 volumes $(p=0.955)$, with a saddle point at $35 \mathrm{~mL}$. Higher cake solids $(>20 \%)$ were achieved at 388 a speed of $1600 \mathrm{rpm}$ with lower or higher volumes (Figure 3b). There was an almost perfect 389 interaction between speed and time (elliptical contours), though it was not significant $(p=$ 390 0.954). The quadratic effect of time was reflected; with the maximum being 20 minutes. The 391 optimum cake solids of $13.3 \%$ could be obtained at maximum time of 20 minutes at volume and 392 speed of $35 \mathrm{~mL}$ and $400 \mathrm{rpm}$, respectively. However, cake solids increased to an optimum of $393 \quad 18.7 \%$ at a speed of $1600 \mathrm{rpm}$, beyond which per cent cake solids decreased.

394 At optimal time of 20 minutes and volume of $35 \mathrm{~mL}$, the average per cent cake solids of 16.4 395 (Table 5) could be achieved at speed of $870 \mathrm{rpm}$. Consequently, increasing speed from 870 to $3961600 \mathrm{rpm}$ at constant time of 20 minutes improved per cent cake solids from average of 16.4 to $39718.6 \%$ (Figure 3c). For comparison with the original FS, average $11.2 \%$ cake solids at speed of $398920 \mathrm{rpm}$ can be achieved at about $160 \mathrm{rpm}$, when conditioned with charcoal dust. 
400

401

402

403

404

405

406

407

408

409

410

411

412

413

414

415

416

417

418

419

420

421

422

423

424

425

426 (a)

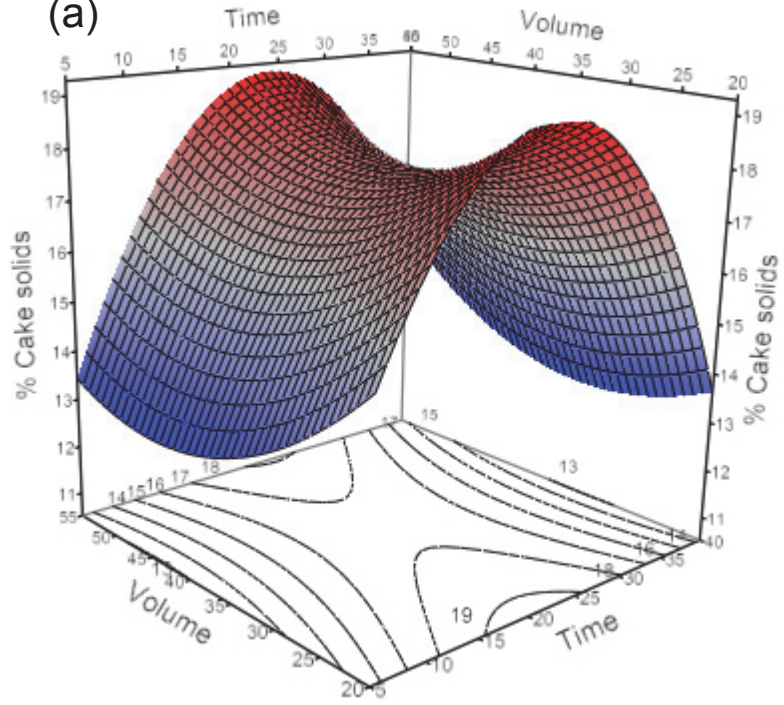

(b)

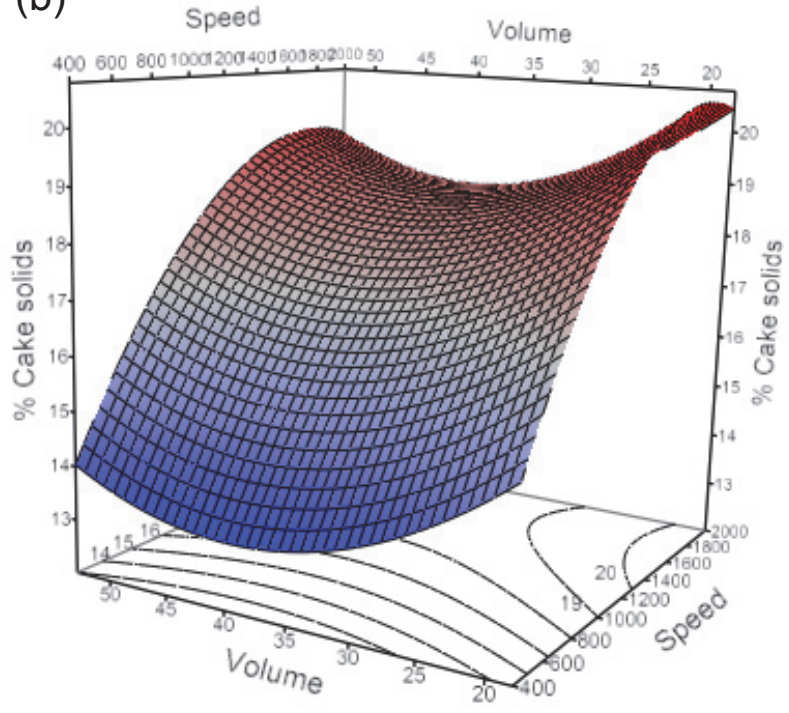

(c)

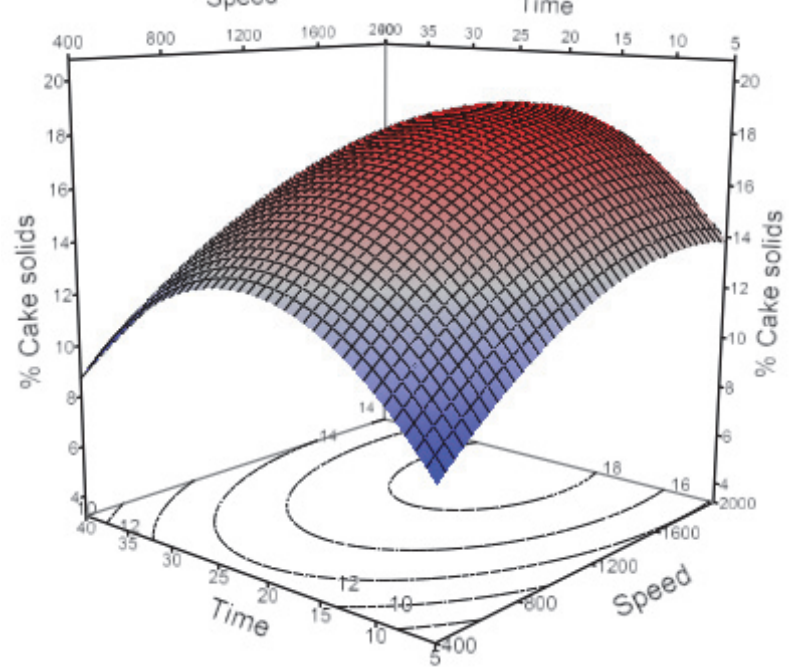

Figure 3 Three-dimensional surface plots of per cent cake solids for charcoal dust-conditioned FS from pit latrine as a function of: (a) volume and time; (b) volume and speed; (d) time and speed. Below each graph is a 2D contour plot showing interaction between the two variables.

\section{Discussion}

\subsection{Use of sawdust and charcoal dust conditioners in centrifugal dewatering of FS}

The average per cent cake solids for original FS, sawdust and charcoal dust conditioned FS were 11.4, 14.2 and 16.4, respectively. Per cent cake solids increased by 24.6 and $43.8 \%$ 
when conditioned with $75 \%$ TS of sawdust and charcoal dust, respectively. The cake solids 428 increase in FS conditioned with charcoal dust is much higher than the observed $28.2 \%$ 429 increment by Albertson and Kopper (1983), when sewage sludge was conditioned with coal 430 fines. The interaction effects for volume and time in original and sawdust conditioned FS 431 signified sedimentation of particles with time. However, the quadratic effect of time, where it 432 takes 20 minutes for cake solids to increase to maximum and thereafter decreases, was 433 significant for sawdust conditioned FS. Centrifugation beyond 20 minutes resulted in re434 suspension of settled solids probably due to high absorptive nature of sawdust (Lin et al., 2001; 435 Luo et al., 2013). The result therefore suggests that sawdust significantly re-absorbed moisture 436 during batch centrifugation to decrease the per cent cake solids after 20 minutes. Therefore, the 437 quadratic effect of time needs to be considered during the operation of a centrifuge by limiting 438 centrifugation time.

439 The use of sawdust and charcoal dust conditioners improved the cake solids recovery due to 440 water absorption and increased porosity of FS cake. Semiyaga et al. (2017b) reported 89 and $44156 \%$ reduction in FS cake moisture after addition of sawdust and charcoal dust, respectively, 442 due to absorption and the remaining percentage may be attributed to improved porosity. The 443 decrease in moisture content of conditioned FS cake after dewatering is comparable to that of 444 sewage sludge cake, when sawdust and coal fly ash additives were increased from 0 to $100 \%$ 445 (Chen et al., 2010; Ding et al., 2014; Lin et al., 2001). The particles of sawdust/charcoal dust are 446 bridged between FS solids, creating voids for water to flow out of the cake. This improvement in 447 porosity makes subsequent management options for separated FS solid and liquid streams 448 simpler. For example, the drying process of solid fraction quickens, since the convective heat 449 from surrounding air could easily be conducted to the interior of the FS cake, thus increasing the 450 interior temperature which affects the diffusion of water and vapour from the interior to the 451 surface, and later evaporated to the ambient (Lei et al., 2009). This can be achieved by 452 conventional drying of FS on sand beds, enhanced by greenhouse effect or use of solar dryers 453 (Murray Muspratt et al., 2014). The later enhanced technologies could be more feasible in an 454 urban slum setting due to space limitations. Further, the improved porosity of FS cake can 455 enhance the composting process through increased internal spaces for air flow (Lin et al., 456 2001). Subsequently, usage of sawdust/charcoal dust conditioned FS as an organic soil 457 amendment improves soil productivity, not only because of nutrients present in FS, but also 458 increased aeration and water holding capacity of soils due to improved porosity (Kelley and 459 Martens, 1984). 


\subsection{Effect of rotational speed on cake solids yield}

461 Generally, the higher the centrifugation speed, the more the centrifugal acceleration and hence

462 faster sedimentation rate of solids for the original and sawdust/charcoal dust conditioned FS.

463 This is in agreement with a study by Garrido et al. (2003) who reported increased

464 sedimentation with centrifugation rotational speed. In addition, conditioned FS contains larger 465 and more particles than original FS (Table 3), hence the increased sedimentation rate of 466 conditioned FS, since larger particles tend to settle out quicker (Chu and Lee, 2002). Moreover, 467 the particles of sawdust and charcoal dust are bridged between the original FS particles. These 468 break the capillary water between FS particles, hence, creating voids (Schubert, 1984).

469 Further rotational speeds set up centrifugal compaction of settled solid particles causing more 470 water to be released, hence the observed drier cake after physical conditioning with 471 sawdust/charcoal dust. However, charcoal dust conditioned FS yielded dryer cake solids than 472 sawdust (16 and $14 \%$ cake solids, respectively) at similar rotational speeds. This could be 473 because the density of charcoal dust $\left(869 \mathrm{kgm}^{-3}\right)$ is much higher than that of sawdust $\left(174 \mathrm{kgm}^{-}\right.$ $474{ }^{3}$ ) (Table 2), since Vesilind and Zang (1984) reported centrifugal compaction to be a function of 475 particle density. Hence, more compaction takes place in charcoal dust conditioned FS and 476 consequently more per cent cake solids yield. Therefore, the observed increase in $\%$ cake 477 solids with speeds in original and sawdust conditioned FS could be due to increasing 478 compaction of FS cake. An interesting result is for charcoal dust conditioned FS, where an 479 optimum speed of $1600 \mathrm{rpm}$ occurred, beyond which per cent cake solids reduced. The higher 480 density of charcoal dust particles could have caused the sedimentation and compaction 481 processes to be completed by this speed. FS conditioning results therefore depict increased 482 capacity of centrifuges to handle more FS volumes and hence significant reductions in space 483 requirements in urban slums.

\subsection{Implications on faecal sludge management in urban slums}

485 A typical centrifuge is known to consist of a rotor, spin by a drive motor which is powered by 486 electrical supply that makes it to rotate (Gutierrez, 2005). The observed reduced centrifugation 487 speeds after modifying FS properties with the sawdust/charcoal dust conditioners can be 488 realised by hand-powered centrifuge devices. Here, a user physically spins the device and 489 energy is transformed into rotation of the rotor through gears. This could help in dewatering of 490 FS from slum areas that are not supplied with electricity, or where the use of electricity to run 491 the centrifuge is more expensive as compared to hand-powered. In some cases, cycle-powered 
centrifuge devices could also be appropriate, where the pedalling actions of bi/tricycles are

493 transformed into rotor motion. Never-the-less, hand/cycle-powered centrifuge devices could

494 become energy intensive in times where people have to operate them for long durations, owing

495 to large volumes of emptied FS. In such cases, the centrifuge design could be modified to allow

496 a 12 volts DC battery power source (Turvaville et al., 1999) to rotate the devices in slum areas.

497 The DC battery can be recharged from places with electricity and used for running centrifuge or

498 usage of DC solar batteries charged by solar panels could be appropriate since solar energy is

499 available in most of the low-income countries. Local fabrication of hand/cycle powered

500 centrifuge devices can provide a low cost technology that is easily adoptable by low-income

501 urban slum population.

502 After centrifugation, the separated liquid fraction (centrate/leachate) could be further treated in a 503 low-cost crushed filter (sand, soil or lava rock) unit such as that developed by Katukiza et al. 504 (2014) to reduce the pollutant loads from wastewater in urban slums. The treated centrate is 505 likely to suit non-portable purposes such as irrigation of tower gardens for urban agriculture 506 (Kulabako et al., 2011), mortar additive for construction purposes (Katukiza et al., 2014), or 507 toilet flushing (Hamawand and Lewis, 2016). This has the potential to improve health and 508 increase environmental protection that would otherwise emanate from indiscriminate disposal of 509 untreated FS in a slum environment. The dewatered solid fraction can be transformed into a 510 number of products utilisable by the slum population (Semiyaga et al., 2015).

511 Implementation of centrifugation technology in dewatering FS at household or community level 512 in slums requires FS emptying and treatment of the separated FS streams, before and after 513 centrifugation, respectively. People/slum dwellers are involved during execution of these 514 activities at all stages of emptying, dewatering and treatment/end-use of liquid and solid 515 streams. Since raw emptied FS contains high pathogen load (Still and Foxon, 2012), this poses 516 health risks to the users of the centrifugation technology. Therefore, a need for further 517 investigation on the fate of pathogens such as E.coli and helminth eggs across centrifugal 518 dewatering process in an urban slum setting is necessary in order to protect the operators of 519 this process and subsequent processes/handling and/or reuse downstream.

521 The centrifugation rotational speed has been identified as a key design parameter. In addition, 522 the centrifugation time significantly influenced dewatering of sawdust conditioned FS. The effect 
523 of time on percent cake solids yield was quadratic, with an optimum value at 20 minutes. 524 Centrifugation beyond this time further reduced per cent cake solids due to re-absorption of 525 moisture by the dewatered cake conditioned with sawdust/charcoal dust.

526 When FS was conditioned with charcoal dust, the saddle point created at midway volumes (35 527 to $40 \mathrm{~mL}$ ) suggested that operating a centrifuge when full or less than half-full would yield higher 528 cake solids. For original and sawdust conditioned FS, optimum cake solids were obtained 529 between volume of 40 to $45 \mathrm{~mL}$. Therefore, making the centrifuge container full lowered the per 530 cent cake solids. Charcoal dust conditioned FS exhibited an optimum per cent cake solids yield 531 at a speed of 1600 rpm, but cake solids were linearly increasing with speed for original and 532 sawdust conditioned FS. Rotational speed required to achieve a certain per cent cake solids 533 reduced with addition of sawdust and charcoal dust. Such low rotational speeds can be 534 achieved by hand/cycle powered centrifuge devices, fabricated locally, thereby, providing a low 535 cost technology adaptable for dewatering FS in low-income urban slums. The next stage would 536 be to develop a pilot-scale centrifuge unit and test it with FS from sanitation facilities commonly 537 used by urban slum dwellers, such as pit latrines.

\section{Acknowledgements}

539 This research was carried out as part of the project titled "Stimulating Local Innovation on 540 Sanitation for the Urban Poor in Sub-Saharan Africa and South-East Asia", which is funded by 541 the Bill \& Melinda Gates Foundation, USA (Grant Number OPP1029019), through UNESCO542 IHE in partnership with Makerere University.

\section{References}

Albertson, O.E., Kopper, M., 1983. Fine-coal-aided centrifugal dewatering of waste activated sludge. Water Pollut. Control Fed. 55, 145-156.

APHA/AWWA/WEF, 2012. Standard Methods for the Examination of Water and Wastewater,

Blackett, I., Hawkins, P., Heymans, C., 2014. The Missing Link in Sanitation Service Delivery. A Review of Fecal Sludge Management in 12 Cities, Water and Sanitation Program: Research brief.

Brar, S.K., Verma, M., Tyagi, R.D., Valéro, J.R., Surampalli, R.Y., 2006. Efficient centrifugal recovery of Bacillus thuringiensis biopesticides from fermented wastewater and wastewater sludge. Water Res. 40, 1310-1320. doi:10.1016/j.watres.2006.01.028 
Broadbent, T., 2001. Centrifuges: the choice. Filtr. Sep. 38, 30-33.

555

556

557

558

559

560

561

562

563

564

565

566

567

568

569

570

571

572

573

574

575

576

577

578

579

580

581

582

583

584

585

586

587

588

Buerger, R., Concha, F., 2001. Settling velocities of particulate systems : 12 . Batch centrifugation of flocculated suspensions. Int. J. Miner. Process. 63, 115-145.

Burton, C.H., 2007. The potential contribution of separation technologies to the management of livestock manure. Livest. Sci. 112, 208-216. doi:10.1016/j.livsci.2007.09.004

Chen, C., Zhang, P., Zeng, G., Deng, J., Zhou, Y., Lu, H., 2010. Sewage sludge conditioning with coal fly ash modified by sulfuric acid. Chem. Eng. J. 158, 616-622. doi:10.1016/j.cej.2010.02.021

Chu, C.P., Lee, D.J., 2002. Centrifugation of polyelectrolyte flocculated clay slurry. Sep. Sci. Technol. 37, 591-605. doi:10.1081/SS-120001449

Diener, S., Semiyaga, S., Niwagaba, C.B., Muspratt, A.M., Gning, J.B., Mbéguéré, M., Ennin, J.E., Zurbrugg, C., Strande, L., 2014. A value proposition: Resource recovery from faecal sludge-Can it be the driver for improved sanitation? Resour. Conserv. Recycl. 88, 32-38. doi:10.1016/j.resconrec.2014.04.005

Ding, A., Qu, F., Liang, H., Guo, S., Ren, Y., Xu, G., 2014. Effect of adding wood chips on sewage sludge dewatering in pilot-scale plate-and frame filter press process. R. Soc. Chem. Adv. 4, 24762-24768. doi:10.1039/c4ra03584d

Drury, D.D., Berch, C., Lee, R., Arjunan-Lee, S., Baker, C., 2002. Comparison of Belt Press vs. Centrifuge Dewatering Characteristics for Anaerobic Digestion. Proc. Water Environ. Fed. 2002, 123-130.

Garrido, P., Concha, F., Bürger, R., 2003. Settling velocities of particulate systems: 14. Unified model of sedimentation, centrifugation and filtration of flocculated suspensions. Int. J. Miner. Process. 72, 57-74. doi:10.1016/S0301-7516(03)00087-5

Gold, M., Dayer, P., Faye, M.C.A.S., Clair, G., Seck, A., Niang, S., Morgenroth, E., Strande, L., 2016. Locally produced natural conditioners for dewatering of faecal sludge. Environ. Technol. 1-13. doi:10.1080/09593330.2016.1165293

Gutierrez, A.G., 2005. Handheld and hand-powered centrifuge device. U.S. Pat. 6,905,454, issued June 14. doi:10.1126/science.Liquids

Hamawand, I., Lewis, L., 2016. Innovative pit design and sludge dewatering for rural areas. J. Environ. Chem. Eng. 4, 3775-3778. doi:10.1016/j.jece.2016.08.009

Katukiza, A.Y., Ronteltap, M., Niwagaba, C.B., Kansiime, F., Lens, P.N.L., 2014. A two-step crushed lava rock filter unit for grey water treatment at household level in an urban slum. J. Environ. Manage. 133, 258-267. doi:http://dx.doi.org/10.1016/j.jenvman.2013.12.003

Kelley, W.D., Martens, D.C., 1984. Agricultural Use of Sewage Sludge : A Literature Review. Virginia, USA. 
Kulabako, N.R., Ssonko, N.K.M., Kinobe, J.R., 2011. Greywater characteristics and reuse in tower gardens in peri-urban areas - experiences of Kawaala, Kampala, Uganda. Open Environ. Eng. 4, 147-154.

Lei, Z., Dezhen, C., Jinlong, X., 2009. Sewage sludge solar drying practise and characteristics study, in: Asia-Pacific Power and Energy Engineering Conference, APPEEC. pp. 1-5. doi:10.1109/APPEEC.2009.4918741

Lin, Y.-F., Jing, S.-R., Lee, D.-Y., 2001. Recycling of wood chips and wheat dregs for sludge processing. Bioresour. Technol. 76, 161-163.

Luo, H., Ning, X. an, Liang, X., Feng, Y., Liu, J., 2013. Effects of sawdust-CPAM on textile dyeing sludge dewaterability and filter cake properties. Bioresour. Technol. 139, 330-336. doi:10.1016/j.biortech.2013.04.035

Murray Muspratt, A., Nakato, T., Niwagaba, C., Dione, H., Kang, J., Stupin, L., Regulinski, J., Mbéguéré, M., Strande, L., 2014. Fuel potential of faecal sludge: calorific value results from Uganda, Ghana and Senegal. J. Water, Sanit. Hyg. Dev. 4, 223-230. doi:10.2166/washdev.2013.055

Nakagiri, A., Kulabako, R.N., Nyenje, P.M., Tumuhairwe, J.B., Niwagaba, C.B., Kansiime, F., 2015. Performance of pit latrines in urban poor areas: A case of Kampala, Uganda. Habitat Int. 49, 529-537. doi:10.1016/j.habitatint.2015.07.005

Nakagiri, A., Niwagaba, C.B., Nyenje, P.M., Kulabako, R.N., Tumuhairwe, J.B., Kansiime, F., 2016. Are pit latrines in urban areas of Sub-Saharan Africa performing? A review of usage, filling, insects and odour nuisances. BMC Public Health 16, 1-16. doi:10.1186/s12889-0162772-z

Pan, J.R., Huang, C., Cherng, M., Li, K.-C., Lin, C.-F., 2003. Correlation between dewatering index and dewatering performance of three mechanical dewatering devices. Adv. Environ. Res. 7, 599-602. doi:10.1016/S1093-0191(02)00052-7

Qi, Y., Thapa, K.B., Hoadley, A.F.A., 2011. Application of filtration aids for improving sludge dewatering properties - A review. Chem. Eng. J. 171, 373-384. doi:10.1016/j.cej.2011.04.060

Schubert, H., 1984. Capillary forces - modeling and application in particulate technology. Powder Technol. 37, 105-116. doi:10.1016/0032-5910(84)80010-8

Semiyaga, S., Okure, M.A.E., Niwagaba, C.B., Katukiza, A.Y., Kansiime, F., 2015. Decentralized options for faecal sludge management in urban slum areas of Sub-Saharan Africa: A review of technologies, practices and end-uses. Resour. Conserv. Recycl. 104, 109-119. doi:10.1016/j.resconrec.2015.09.001

Semiyaga, S., Okure, M.A.E., Niwagaba, C.B., Nyenje, P.M., Kansiime, F., 2017 a. Dewaterability of faecal sludge and its implications on faecal sludge managment in urban slums. Int. J. Environ. Sci. Technol. 14, 151-164. doi:10.1007/s13762-016-1134-9 
Semiyaga, S., Okure, M.A.E., Niwagaba, C.B., Nyenje, P.M., Kansiime, F., 2017b. Enhancing faecal sludge dewaterability and end-use by conditioning with sawdust and charcoal dust. Environ. Technol. Inpress. doi:10.1080/09593330.2017.1300191

Still, D., 2012. Tackling the Challenges of Full pit latrines. Volume 3 : The development of pit emptying technologies. South Africa.

Still, D., Foxon, K., 2012. Tackling the Challenges of Full pit latrines. Volume 1 : Understanding sludge accumulation in VIPs and strategies for emptying full pits. South Africa.

Strande, L., 2014. The Global Situation, in: Strande, L., Ronteltap, M., Brdjanovic, D. (Eds.), Faecal Sludge Management - Systems Approach Implementation and Operation. IWA Publishing, London, UK, pp. 1-14.

Tumwebaze, I.K., Orach, C.G., Niwagaba, C., Luthi, C., Mosler, H.-J., 2013. Sanitation facilities in Kampala slums, Uganda: users' satisfaction and determinant factors. Int. J. Environ. Health Res. 23, 191-204. doi:10.1080/09603123.2012.713095

Turvaville, L.J., Mullen, E., King, F., 1999. Portable DC powered centrifuge. U.S. Pat. $5,924,972$, issued July 20.

UN-HABITAT, 2006. State of the World's cities 2006/2007: 30 Years of Shaping the Habitat Agenda. United Nations Human Settlements Programme. Nairobi, Kenya.

Vesilind, P.A., Zhang, G., 1984. Technique for estimating sludge compactability in centrifugal dewatering. Water Pollut. Control Fed. 56, 1231-1237. doi:10.1016/S0262-1762(99)801229 